\title{
Fully Informed Vulnerable Road Users
}

Simpler, Maybe Better

\author{
Bruno Fernandes \\ ALGORITMI Center \\ University of Minho \\ Braga, Portugal \\ bruno.fmf.8@gmail.com \\ António Capita \\ Instituto Superior Técnico Militar \\ Luanda, Angola \\ antoniojorgecapita@gmail.com
}

\author{
Henrique Vicente \\ Chemistry Department \\ University of Évora \\ Évora, Portugal \\ hvicente@uevora.pt \\ Cesar Analide \\ ALGORITMI Center \\ University of Minho \\ Braga, Portugal \\ analide@di.uminho.pt
}

\author{
Jorge Ribeiro \\ Escola Superior de Tecnologia e Gestão \\ Instituto Politécnico de Viana do Castelo \\ Viana do Castelo, Portugal \\ jribeiro@estg.ipvc.pt \\ José Neves $^{\dagger}$ \\ ALGORITMI Center \\ University of Minho \\ Braga, Portugal \\ jneves@di.uminho.pt
}

\begin{abstract}
Vulnerable Road Users (VRUs) are all those with an increased vulnerability on the road, in particular non-motorised ones. Until now, the emphasis has been in politics more focused on drivers, vehicles and infrastructures. However, recent developments show a shift in other directions, with researchers now devoting efforts to improve VRUs' safety. Hence, this work focuses on pedestrian walking and crossing behaviour, attitudes, motivations and habits, being grounded on an approach to Knowledge Representation and Reasoning centred on logic programming, which establishes a formal logical inference engine that is complemented with an Artificial Neural Network line to computation.
\end{abstract}

\section{CCS CONCEPTS}

- Computing methodologies $\sim$ Knowledge representation and reasoning $\bullet$ Theory of computation $\sim$ Programming logic

\section{KEYWORDS}

Vulnerable Road Users, Knowledge Representation and Reasoning, Logic Programming, Artificial Neural Networks.

\section{ACM Reference format:}

Bruno Fernandes, Henrique Vicente, Jorge Ribeiro, António Capita, Cesar Analide and José Neves. 2019. Fully Informed Vulnerable Road Users Simpler, Maybe Better. In The 21st International Conference on Information Integration and Web-based Applications \& Services Proceedings (iiWAS2019). ACM, Munich, Germany, 5 pages. https://doi.org/10.1145/3366030.3366089

\footnotetext{
(C) 2019 Association for Computing Machinery. ACM acknowledges that this contribution was authored or co-authored by an employee, contractor or affiliate of a national government. As such, the Government retains a nonexclusive, royalty-free right to publish or reproduce this article, or to allow others to do so, for Government purposes only.

(C) 2019 Association for Computing Machinery.

ACM ISBN 978-1-4503-7179-7/19/12 ..\$15.00

https://doi.org/10.1145/3366030.3366089
} 